\title{
Auto-organização da vegetação de caatinga em áreas salinizadas no município de Petrolina-PE
}

Self-organization of caatinga vegetation in salinized areas in the municipality of Petrolina-PE

\author{
A. M. $\operatorname{Santos}^{1 *}$; R. F. Souza ${ }^{1}$; F. C. Castro ${ }^{2}$ \\ ${ }^{\text {I} C o l e g i a d o ~ d e ~ G e o g r a f i a / G T M A G E O, ~ U n i v e r s i d a d e ~ d e ~ P e r n a m b u c o, ~ R o d o v i a ~ B R ~ 203, ~ K m ~ 2, ~ C E P ~ 56328-903 ; ~}$ \\ Petrolina-Pernambuco, Brasil \\ ${ }^{2}$ Mestrado em Ecologia Humana e Gestão Socioambiental/GTMAGEO, Universidade do Estado da Bahia e \\ Universidade de Pernambuco, Rodovia BR 203, Km 2, CEP: 56328-903; Petrolina-Pernambuco, Brasil
}

*antonio.santos@upe.br

(Recebido em 14 de janeiro de 2018; aceito em 16 de agosto de 2018)

\begin{abstract}
A salinização dos solos no semiárido brasileiro é um dos principais problemas enfrentados pelos agricultores e, em alguns casos, comprometendo a biodiversidade das caatingas e, contribuindo para o processo de desertificação. O presente estudo tem como objetivo analisar a dinâmica da auto-organização da vegetação de caatinga em áreas salinizadas e não salinizadas do município de Petrolina, estado de Pernambuco e sua possível contribuição para susceptibilidade à desertificação. A pesquisa foi desenvolvida em duas etapas. Em campo, primeira etapa, foram selecionadas quatro parcelas, sendo coletadas informações da vegetação, solos e interferência antrópica. A segunda etapa foi desenvolvida em laboratório, onde foram confeccionados mapas de uso da terra, análise dos solos e avaliação final da estrutura e organização sistêmica da vegetação. Os resultados indicam que, nas parcelas onde os solos se encontram salinizados, a elevada entropia provocou perda da vegetação e, no processo de auto-organização espécies adaptadas aos ambientes salinos passaram a predominar. Nas parcelas em que os solos apresentaram reduzidos teores de sais não foram verificadas modificações na estrutura da cobertura vegetal. Para reduzir o impacto da presença de sais nas parcelas degradadas o recomendado seria a destinação dessas áreas para preservação. Outras alternativas seriam a inserção da Atriplex numulária, capaz minimizar os impactos da salinização, e o uso de corretivos químicos. Conclui-se que, nas áreas salinizadas o processo de autoorganização da vegetação vem substituindo espécies glicófitas por espécies halófitas, modificando assim, a diversidade de espécies nesses ambientes e contribuindo para os riscos de desertificação sendo necessárias intervenções urgentes.
\end{abstract}

Palavras-chave: Salinização, Semiárido, Degradação dos solos.

Soil salinization in the Brazilian semi-arid region is one of the main problems faced by farmers and, in some cases, damaging the biodiversity of the caatingas and contributing to the desertification process. The present study aims to analyze the dynamics of the self-organization of caatinga vegetation in salinized and non-salinized areas of the municipality of Petrolina, state of Pernambuco - Brazil and its possible contribution to susceptibility to desertification. The research was developed in two stages. In field - first stage - four plots were selected, being collected vegetation information, soils and anthropic interference. The second stage was developed in a laboratory, where maps of land use, soil analysis and final evaluation of the structure and systemic organization of the vegetation were made. The results indicate that, in the plots where the soils are salinized, the high entropy caused loss of vegetation and, in the process of selforganization, species adapted to saline environments became predominant. In the plots where the soils presented reduced salt content, no changes were observed in the structure of the vegetation cover. To reduce the impact of the presence of salts in degraded plots the recommended would be the destination of these areas for preservation. Other alternatives would be the insertion of Atriplex numularia, able to minimize the impacts of salinization, and the use of chemical correctives. It is concluded that in the salinized areas the process of self-organization of vegetation is replacing glycophytes species by halophyte species, thus modifying the diversity of species in these environments and contributing to the risks of desertification, requiring urgent interventions.

Keywords: salinization, semiarid, soil degradation 


\section{INTRODUÇÃO}

A desertificação é um dos principais problemas ambientais enfrentados pelas populações que residem nas regiões secas da terra. Esse problema pode ser definido como a degradação das terras localizadas em ambientes áridos, semiáridos e subúmidos secos, tendo como consequência um conjunto de processos que abrange ações humanas e as variabilidades e/ou mudanças climáticas $[1,2,3]$.

Várias são as causas que culminam com o processo de desertificação, entre elas, pode-se destacar a retirada da cobertura vegetal sem uma prática adequada do manejo dos solos [4]. Tal ação deixa os solos expostos, tornando-os vulneráveis às ações erosivas provocadas pelas precipitações pluviométricas e, ações eólicas, as quais proporcionam perda de nutrientes, tornando os solos susceptíveis à desertificação [2].

Outro problema relacionado à degradação das terras secas é o processo de salinização dos solos. Entende-se por salinização o acúmulo de sais solúveis nos horizontes agricultáveis dos solos como cálcio, magnésio e sódio provocando redução do seu potencial agrícola $[5,6,7]$.

O processo de salinização pode ser proveniente de fatores naturais e/ou humanos. Entre os fatores naturais, podem-se destacar os transportes de sedimentos com presença de sais oriundos de áreas mais altas para as mais baixas, além de depósitos de fósseis de sais que foram sedimentados em épocas remotas, entre outros fatores [7,8].

Em relação aos fatores humanos, o destaque está no uso da água para irrigação. Segundo Brasileiro (2009) [9], o processo de irrigação representa o principal fator de salinização dos solos nas áreas susceptíveis à desertificação.

Inicialmente, a irrigação eleva a produção nas áreas alagadas; porém, com o passar do tempo, haverá redução dessa produção impulsionada pelo acúmulo de sais nos solos, contribuindo, assim, para o processo de desertificação. As áreas destinadas aos grandes projetos de irrigação são as mais vulneráveis à salinização, e boa parte delas, no semiárido brasileiro, estão localizadas próximas ao rio São Francisco [10].

Os problemas relacionados à salinização não se restringem apenas ao semiárido brasileiro, em várias regiões secas do mundo, são encontradas implicações ambientais referentes ao acúmulo de sais nos solos. Implicações que afetam tanto a dinâmica social das populações, assim como a biodiversidade desses ambientes. Pedrotti et al. (2015) [6] destacam que cerca de 7\% dos solos em escala mundial apresentam problemas graves de salinização.

Diante do apresentado, observa-se a grande relevância que tem a problemática da salinização dos solos para os ambientes áridos, semiáridos e subúmidos secos. Nesse contexto, o objetivo deste artigo é analisar a dinâmica de auto-organização da vegetação de caatinga em áreas salinizadas no projeto de irrigação Nilo Coelho, núcleo 11, município de Petrolina, estado de Pernambuco.

\section{EFEITOS DOS SAIS SOBRE A COBERTURA VEGETAL}

De acordo com Dias e Blanco (2010) [11], milhares de hectares de terras destinadas à produção agrícola são degradados devido ao aumento intensivo da salinidade nos solos. Os motivos são vários, porém vale destacar a utilização de água de baixa qualidade no processo de irrigação, uso expressivo de fertilizantes e contaminação dos solos por águas oriundas de processos de inundações. Nas plantas, três efeitos provocados pelo excesso de sais nos solos devem ser destacados. São eles: o efeito osmótico; a plasmólise e a toxidade.

As raízes das plantas têm a habilidade de retirar a água dos solos, isso porque elas funcionam como uma esponja natural que absorvem a solução líquida e os nutrientes encontrados nos solos. Esse processo só é possível por causa das forças de embebição do material das raízes, que é superior às forças com que o solo retém a água. Com a presença de sais nos horizontes superficiais dos solos, a força com que a água é retida aumenta impossibilitando a absorção por parte das plantas, concretizando, assim, o efeito osmótico $[6,11]$.

Já o fenômeno da plasmólise proporciona que a planta apresente perda de água para o solo devido à alta quantidade de sais solúveis encontrados naquele local. Isso é possível porque a alta 
concentração dos sais no solo tem força maior do que a força de embebição das raízes. Então, a água é retirada das células e repassada para o solo salinizado [6].

Quanto aos efeitos tóxicos, esses fazem com que as plantas, a partir do momento em que elas passam a absorver grandes quantidades de sais, com destaque para os bicarbonatos, cloretos e sódio, encontrados na água, proporcionam intoxicações [12].

Diante do apresentado, parte das plantas localizadas nas regiões salinizadas não apresentam resistência a presença de sais nos solos. Essas espécies são conhecidas como glicófitas, as quais são sensíveis a ambientes salinos. Por outro lado, As plantas que têm habilidade de adaptação em solos salinizados são conhecidas como halófitas [7].

\section{A TEORIA GERAL DOS SISTEMAS E A AUTO-ORGANIZAÇÃO DOS SISTEMAS}

Os estudos relacionados à salinização e seus impactos sobre a estrutura fitogeográfica da vegetação de caatinga podem ser trabalhado a partir da perspectiva da Teoria Geral de Sistemas (TGS), desenvolvida por Bertalanffy na primeira metade do século XX. Bertalanffy (1973) [13], biólogo e filósofo austríaco, define o sistema como a inter-relação de uma série de elementos, mantendo sempre relações entre si.

Para Morin (1997) [14], o sistema é um todo organizado por elementos que mantêm plenas interligações entre eles. A observação pontuada por esse autor é que a interligação de elementos por si só não representa ou forma um sistema. Para formação de um sistema, há necessidade de que a interação funcione como um todo.

Segundo Christofoletti (2002) [15], a matéria, a energia e a estrutura são os elementos básicos, que compõem um sistema. A matéria é caracterizada como a parte instável e que será movimentada pelo sistema. A energia é a mola mestre que impulsiona o funcionamento do sistema, realizando, de certa forma, o trabalho. Já a estrutura será as relações dos componentes (elementos) do sistema.

O sistema pode ser aberto ou fechado. O primeiro é o sistema que sempre manterá relações completas com o meio externo. Esse meio externo será tudo que estiver presente fora do sistema. O sistema irá trocar energia e matéria com o ambiente externo. Já o sistema fechado estará fazendo somente a troca de energia com o meio e nunca fará troca de matéria [16].

A vegetação atua como um sistema aberto, visto que troca matéria e energia com os demais sistemas a exemplo do sistema climático, pedológico entre outros. Qualquer entrada de energia ou matéria de forma desproporcional poderá ocasionar perturbação no sistema a partir da entropia.

A entropia é a desordem, a desorganização, a perturbação que se encontram no ambiente quando o mesmo é perturbado. A partir do momento em que um ambiente está em ordem e, é perturbado, por um corpo estranho a entropia aumenta quebrando o estado de estabilidade até então vigente. A partir daí, e com o tempo, o sistema irá se auto-organizar [17]. Coelho (2001) [18] reforça que a entropia corresponde a uma degradação energética e, paralelamente organizacional.

\section{MATERIAL E MÉTODOS}

\subsection{CARACTERIZAÇÃO E LOCALIZAÇÃO DA ÁREA DE ESTUDO}

A pesquisa foi realizada no município de Petrolina, estado de Pernambuco. Para o desenvolvimento da mesma, foi selecionado o Projeto Senador Nilo Coelho (PSNC N-11), área com presença de solos salinizados e que desde o ano de 2016 foi montada uma estação de monitoramento ambiental por parte do Grupo de Trabalho em Monitoramento Ambiental, Geotecnologia e Ensino (GTMAGEO).

O município de Petrolina está localizado no semiárido pernambucano (Figura 1). Possui 293.962 habitantes, segundo o censo do IBGE de 2010 [19], com estimativa de 300.00 habitantes para o ano de 2018. O clima predominante na região é o semiárido com média pluviométrica anual em torno de $431,8 \mathrm{~mm}$. As chuvas são concentradas no verão, e a temperatura média anual é de $26,2^{\circ} \mathrm{C}[20]$. 
O Projeto Senador Nilo Coelho, N-11, teve seus primeiros estudos para implantação na década de 1960, tendo o apoio da Superintendência do Desenvolvimento do Nordeste (SUDENE) e da Companhia de Desenvolvimento do Vale do São Francisco (CODEVASF) [21].

Atualmente, o Núcleo-11 possui uma população de 3.500 habitantes. A produção agrícola é bem diversificada com produções de: manga; acerola; goiaba; banana; uva; entre outras espécies frutíferas [21].

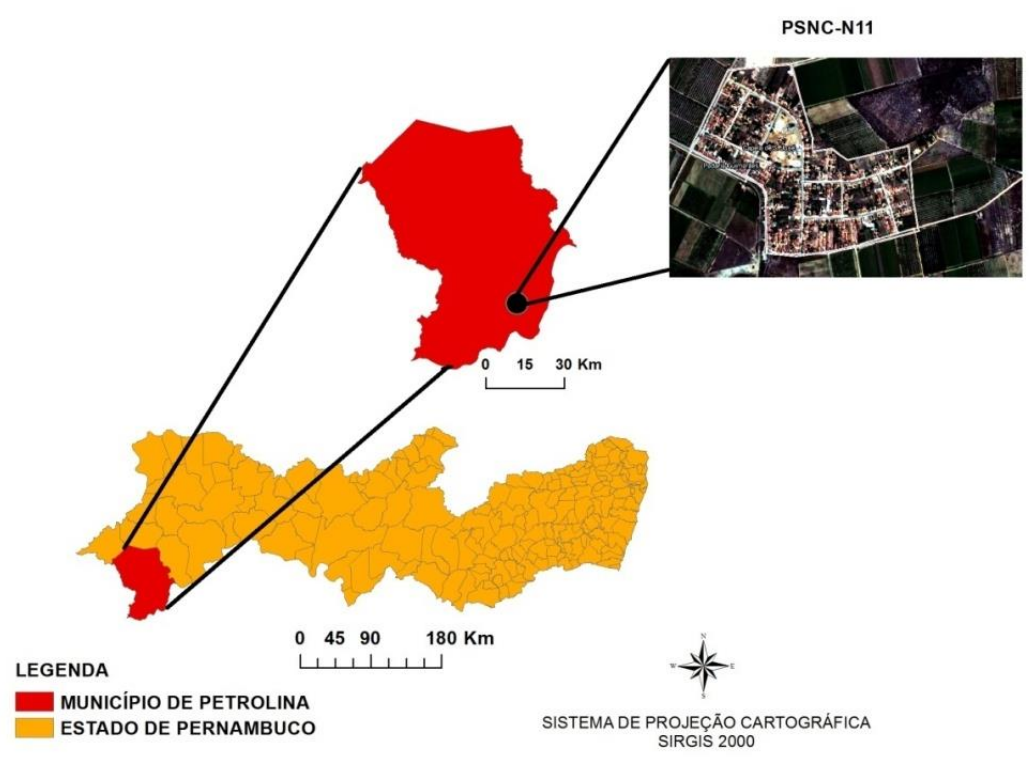

Figura 1: Localização da área de estudo no Projeto Senador Nilo Coelho, N-11- Petrolina Permambuco-Brasil.

\subsection{PROCEDIMENTOS METODOLÓGICOS}

Para a construção deste trabalho, foram selecionadas, em campo, 4 parcelas de $400 \mathrm{~m}^{2}$. Em cada parcela, foram coletadas, inicialmente, informações sobre as espécies vegetais predominantes. Para isso, utilizou-se a metodologia de Cavalcanti (2014) [22], a qual subdivide a estrutura vegetal em três fragmentos: herbáceo; arbustivo e arbóreo. Para cada fragmento, verificaram-se as espécies predominantes.

Ainda nas parcelas verificou-se o estrato vegetal predominante. Para isso, empregou-se a classificação de Cavalcanti (2014) [22], a qual destaca o piso florestal, subdossel, dossel e o estrato emergente.

Para a identificação das espécies vegetais, foram utilizados dois parâmetros, sendo um bibliográfico e outro laboratorial. O primeiro seguiu a classificação das espécies vegetais sugeridas por Siqueira Filho (2012) [23], enquanto que a fase laboratorial foi procedida com coleta de folhas em campo e identificação das espécies em laboratório.

Além da coleta das espécies vegetais, foi, também, empregada análise descritiva do uso da terra, observando as intervenções antrópicas. Para cada parcela foram coletadas as coordenadas geográficas por meio do aparelho receptor de GPS (Sistema de Posicionamento Global). Esses pontos serviram para delimitar as parcelas e contribuir com o mapeamento de uso da terra.

O mapeamento de uso e cobertura da terra foi produzido a partir de uma imagem orbital gerada pelo satélite RapidEye, obtida no mês de maio de 2014. Parplies et al. (2016) [24] apontam que o RapidEye é um dos melhores satélites na captação de imagens de média resolução. É composto por um conjunto de 5(cinco) satélites lançados na órbita da Terra com o propósito de coletar imagens com resolução espacial de aproximadamente $5 \mathrm{~m}$ conforme a sua programação. São oferecidas imagens em 5(cinco) faixas espectrais: Azul; Verde; Vermelha; Vermelho Limítrofe e o Infravermelho próximo. 
A partir das observações de campo, foram selecionadas 4(quatro) classes de uso: solo exposto; caatinga densa; caatinga esparsa e vegetação herbácea/pastagem. Para cada classe, foram retiradas da imagem de satélite 40(quarenta) amostras espectrais. Em seguida, utilizando o software ArcGis, a imagem foi submetida ao processo de classificação supervisionada. De acordo com Cruz e Ribeiro (2008) [25], a classificação supervisionada visa aglomerar os pixels que apresentam informações espectrais semelhantes, gerando, assim, um mapa ou uma carta de uso da terra.

Ainda em campo, coletou-se, para cada parcela, uma amostra do solo nos $30 \mathrm{~cm}$ iniciais. Esses materiais foram analisados no laboratório de Solos do IF Sertão - PE, Campus Zona Rural, com o intuito de aferir o grau de salinidade através dos testes de pH (Potencial Hidrogeniônico) e CE (Condutividade Elétrica).

$\mathrm{O} \mathrm{pH}$ vai classificar o solo em alcalino ou ácido a partir da escala da Figura 2. Na escala, a solução será neutra se permanecer no valor 7. Quanto mais se aproximar do número 0 (zero), a acidez aumenta e, quanto mais se aproximar de 14, será uma base, diminuindo a acidez do solo.

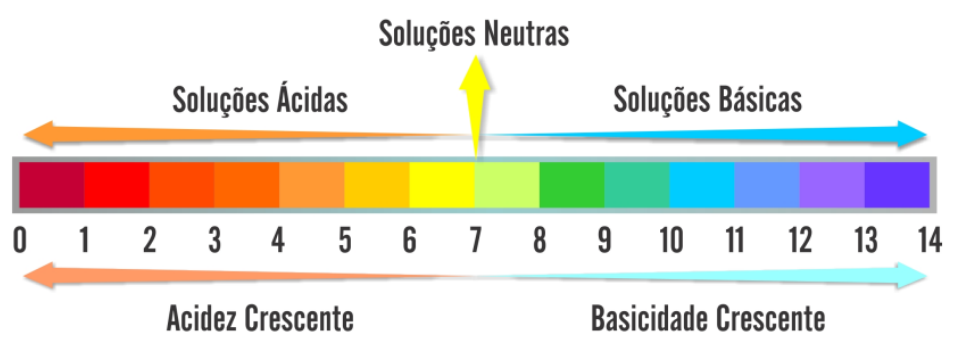

Figura 2: Escala para análise de pH. Fonte: Científica.com (2010)

A relação entre a CE e o teor de sais no solo foi baseada na classificação de Richards (1954) [26], a qual pode ser conferida na tabela 1.

Tabela 1: Classes de salinidade do solo em relação aos efeitos na vegetação. Fonte: Richards (1954)

\begin{tabular}{cc}
\hline CE $\left(\mathbf{d S ~ \mathbf { ~ m } ^ { - }} \mathbf{}^{\mathbf{}}\right)$ & Classes \\
\hline$<2$ & Não salino \\
$2-4$ & Ligeiramente salino \\
$4-8$ & Moderadamente salino \\
$8-16$ & Altamente salino \\
$>16$ & Extremamente salino \\
\hline
\end{tabular}

\section{RESULTADOS E DISCUSSÃO}

\subsection{FUNCIONAMENTO SISTÊMICO DA VEGETAÇÃO EM ÁREAS SALINIZADAS}

\subsubsection{Parcela de amostragem 1}

A figura 3A apresenta o mapa de uso e ocupação da parcela 1. Observa-se que, em toda parcela, ocorre presença apenas de vegetação herbácea, a exemplo do bredo (Amaranthus viridis) e solo exposto (Figura 4). Entende-se por vegetação de estrutura herbácea, segundo Cavalcanti (2014) [22], plantas que não possuem lenha, ou seja, madeira.

O bredo, herbácea presente na parcela 1, é uma planta que se adapta muito bem a solos com presença de sais. É tido por muitos agricultores como uma praga que se prolifera com facilidade e rapidez. 

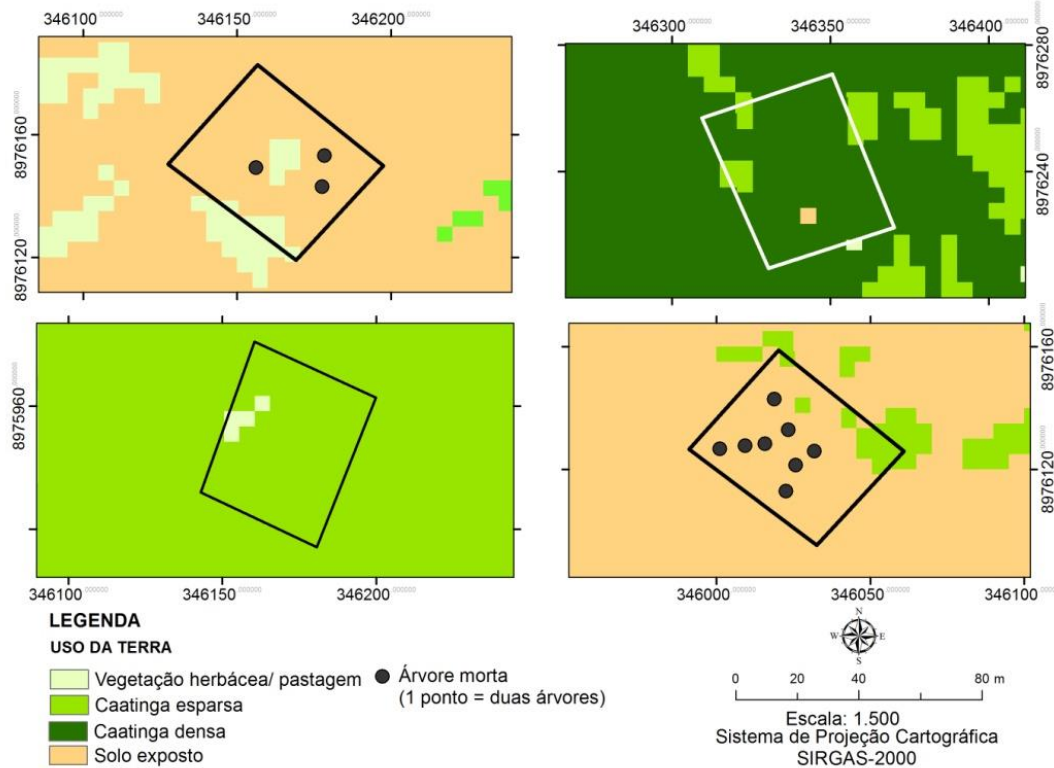

Figura 3: Mapa de uso e ocupação da parcela $1(A)$, parcela $2(B)$, parcela $3(C)$ e parcela $4(D)$
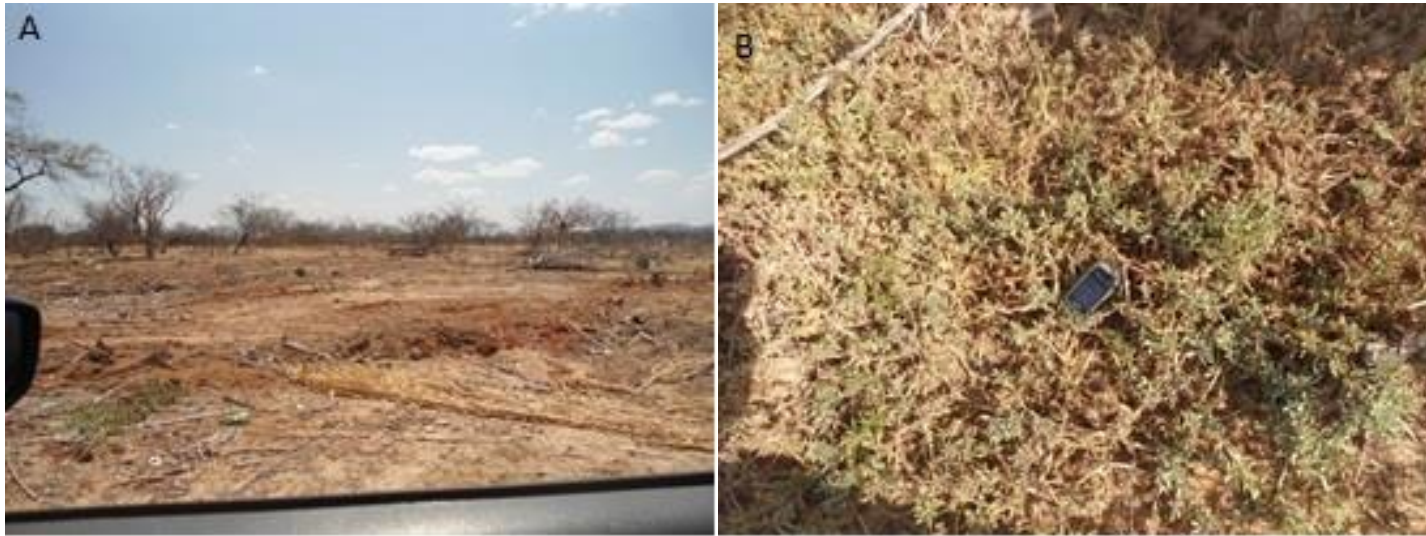

Figura 4: Estrutura de uso da terra encontrada na parcela 1: (A) solo exposto e (B) presença do Bredo (Amaranthus viridis)

A presença da espécie citada anteriormente é justificada pela análise química e as características do solo local. Os resultados laboratoriais apontam que o solo da referida parcela está moderamente salino (Tabela 2), isso porque o pH apresentou 6,26 e a CE 7,971 dSm- ${ }^{1}$. De acordo com Ribeiro (2010) [5], os solos com problemas de salinização apresentam pH menor ou igual a 8,5. Em relação a CE, o solo pode ser considerado salino se o valor for maior ou igual a 2 dSm-1 [26].

Tabela 2: pH e CE dos solos das parcelas

\begin{tabular}{ccc}
\hline PARCELA & $\mathrm{pH}$ & $\mathrm{CE} \mathrm{dSm}^{-1}$ \\
\hline 1 & 6,26 & 7,971 \\
2 & 6,05 & 2,22 \\
3 & 6,56 & 1,88 \\
4 & 8,10 & 6,23 \\
\hline
\end{tabular}

O solo da parcela 1 é o Neossolo Flúvico que, de acordo com a EMBRAPA (2006) [27], apresenta na sua composição sedimentos provenientes de origem fluvial. São compostos por uma série de camadas que se diferem a depender dos diferentes estágios de deposição das águas 
fluviais. Sua drenagem varia entre boa a imperfeitamente drenada. São solos com alto potencial para inundações e, consequentemente, possuem alto risco de acúmulo de sais solúveis, contribuindo com o processo de salinização do ambiente em que está inserido.

Por ser um solo de acumulação fluvial, e pelas características do terreno, percebeu-se em campo que a área encontra-se próxima a um córrego intermitente. No ano de 2004, houve uma forte precipitação pluviométrica na região a qual proporcionou um grande acúmulo de água nesse local. Segundo relatos dos moradores da região, a concentração de água permaneceu por aproximadamente 4 meses, após as chuvas.

A citada concentração de água provocou o processo de salinização natural dos solos nesse local. A água em excesso infiltrou e entrou em contato com os sais presentes no saprólito ou próxima à rocha-matriz, ao ocorrer a evasão da água o efeito de capilaridade trouxe a água do interior do solo à superfície. A água evaporou e os sais se fixaram na superfície do solo como pode ser observado nas Figuras 5A e 5B.
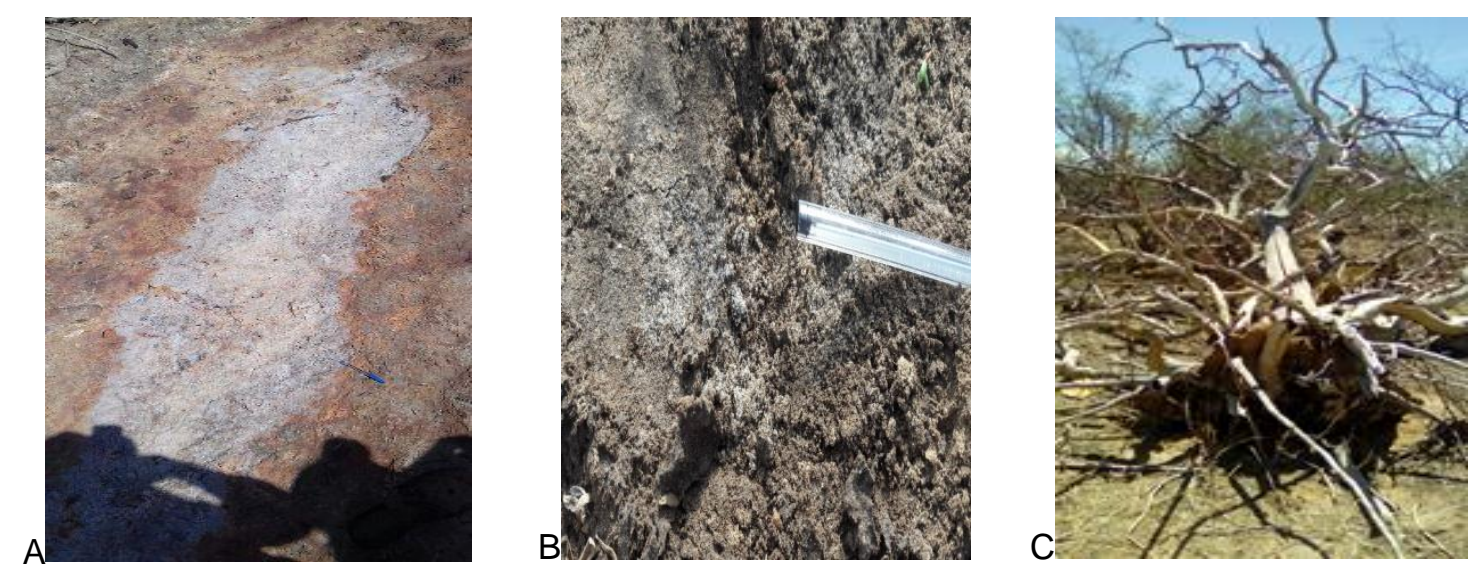

Figura 5: Neossolo Flúvico com presença de sais na superfície - parcela de amostragem 1 (A e B) e baraúna morta pelo processo de salinização $(C)$.

Após o processo de salinização, houve mudanças na paisagem natural da parcela analisada, ou seja, o sistema foi submetido a mudanças bruscas. Levando em consideração a perspectiva da auto-organização, o sistema teve a intrusão da água procedida pela ascensão e acúmulo de sais, ou seja, entrada de matéria e energia em quantidades suficientes para provocando uma conturbação interna.

De acordo com Amorin (2012) [16], a conturbação referida anteriormente trata-se do processo de entropia, ou seja, desordem no sistema. A perturbação extinguiu das áreas salinizadas espécies como a baraúna (Schinopsis brasiliensis), juazeiro (Ziziphus joazeiro), umbuzeiro (Spondias tuberosa) entre outras que predominavam nesse local. Na parcela 1 , foram encontradas estruturas arbóreas de grande porte mortas devido ao processo de aumento da entropia provocada pela intrusão de sais no sistema (Figura 5C). Na parcela de estudo, atualmente, percebe-se que o processo de reorganização do sistema apresenta espécies vegetais resistentes aos sais, ou seja, espécies halófitas a exemplo do Bredo.

\subsubsection{Parcela de amostragem 4}

A parcela 4 está em uma área salinizada sobre o Neossolo Flúvico, o mesmo encontrado na parcela 1. Os valores de pH $(8,10)$ e CE 6,23dSm-1 indicam a salinização desses solos (Tabela 2). Levando em consideração a classificação de Richards (1954) [26], a partir do valor da CE, os Neossolos Flúvicos na parcela 4 são moderadamente salinos.

$\mathrm{O}$ uso da terra na referida parcela tem como predomínio o solo exposto e pequenas manchas de caatinga esparsa (Figura 3D). Em campo, verificou-se a presença de espécies vegetais como o bredo entremeado com o solo exposto e, nas manchas de caatinga esparsa, detectou-se a presença da algaroba (Prosopis juliflora).

Diante das espécies vegetais vivas, encontradas em campo, as mesmas são resistentes a áreas salinizadas. A algaroba é uma espécie de planta arbórea, que se desenvolve em solos de fertilidade 
baixa de regiões áridas e semiáridas [28]. São cultivadas para produção de ração animal, sombreamento, produção de madeira, lenha e carvão vegetal [29]. Assim como o bredo, a algaroba, segundo Wakie et al. (2016) [30] e Al-Soqeer et al. (2017) [28], apresenta grande resistência a solos salinizados.

$\mathrm{Na}$ área de solo exposto, foram detectadas 16 árvores mortas como imburanas (Commiphora leptophloeos), jurema-preta (Mimosa tenuiflora), baraúnas, entre outras (Figura 6). Problema e processos semelhantes ao encontrado na parcela 1.
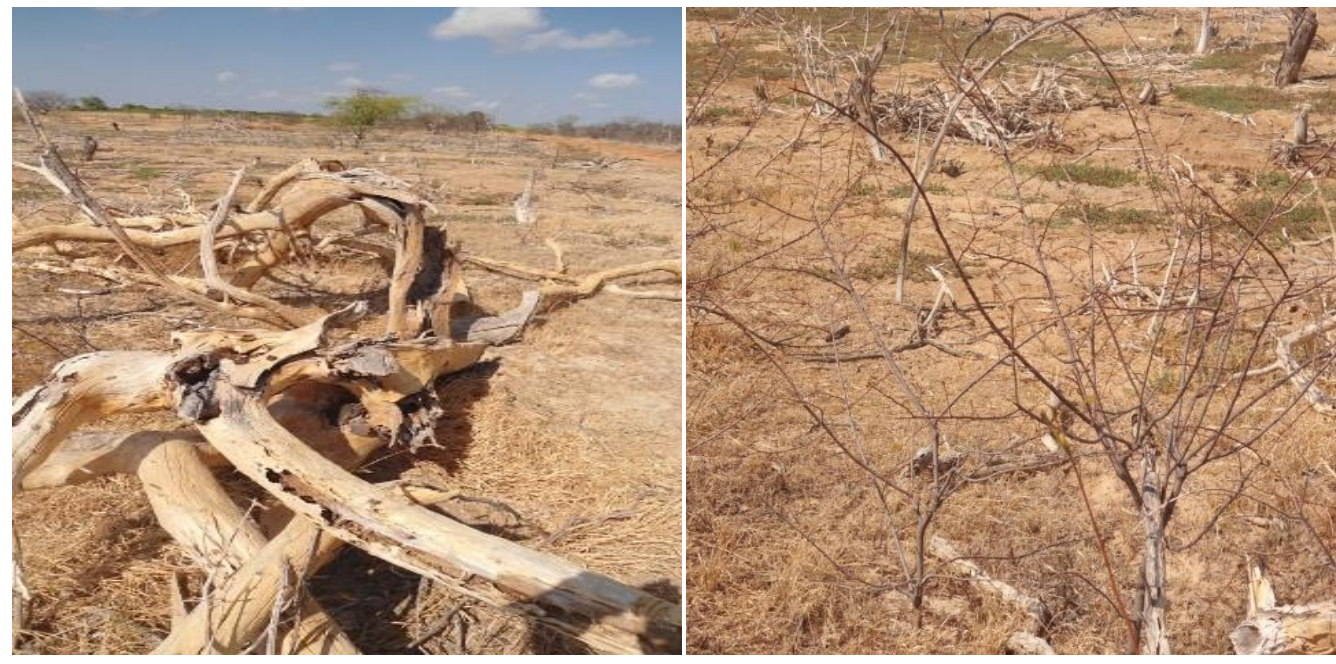

Figura 6: Vegetação morta devido ao processo de salinização na parcela de amostragem 4

A partir da concepção de Dias e Blanco (2010) [11], a vegetação da parcela 4, onde se detectou uma forte influência do solo salinizado, foi eliminada a partir dos processos osmóticos, da plasmólise e intoxicações.

Em relação ao processo de auto-organização do sistema na parcela 4, observa-se que a entrada de sais solúveis provocou uma conturbação no sistema. Posteriormente, o sistema se reorganizou, surgindo espécies vegetais que não predominavam naquela área, ou seja, espécies halófitas resistentes ao solo salinizado a exemplo do Bredo e da Algaroba.

Tanto na parcela de amostragem 1, quanto na parcela 4, o grau de salinização é um fator que irá contribuir no processo de desertificação dessa área, isso porque, nesses locais, o solo terá sua capacidade de produção agrícola reduzida, assim como, perderá seu potencial no desenvolvimento e manutenção de várias espécies vegetais da caatinga.

\subsection{FUNCIONAMENTO SISTÊMICO DA VEGETAÇÃO EM ÁREAS NÃO SALINIZADAS}

\subsubsection{Parcela de amostragem 2}

O solo da parcela é o Argissolo Amarelo, o qual pode ser caracterizado com razoável concentração de argila no horizonte Bt. Segundo Silva, Silva e Barros (2010) [31], os Argissolos no semiárido são rasos e apresentam pedregosidade. Em relação à salinização, o pH foi de 6,05 enquanto que a CE apresentou 2,22 $\mathrm{dSm}^{-1}$ (Tabela 2). Diante do apresentado, o $\mathrm{pH}$ foi considerado neutro e a CE, segundo Richards (1954) [26], classifica o solo em ligeiramente salino, porém muito próximo da categoria de solos não salinos.

O reflexo da análise do solo reflete na estrutura de uso e cobertura vegetal na parcela. Observase, na Figura 3B, o predomínio da caatinga densa e pequenas manchas de vegetação herbácea entremeadas com caatinga esparsa. No contexto geral, a tipologia predominante é a caatinga lenhosa subdividida entre espécies arbóreas e arbustivas (Figura 7). Dos quatro extratos da vegetação analisados, na referida parcela, estão presentes o piso florestal, subdossel e dossel com ausência do extrato emergente.

As espécies arbustivas predominantes foram a canafístula (Senna trachypus) e a malva branca (Waltheria Americana). Em relação às espécies arbóreas, predominam Jurema-preta; Juazeiro; 
facheiro (Pilosocereus pentaedrophorus); mandacaru (Cereus jamacaru) e angico de caroço (Anadenanthera Colubrina). Em relação aos fragmentos herbáceos, destaca-se o quipá (OpuntiaInamoena ou TacingaInamoena).

Ao comparar essa parcela com as parcelas 1 e 4 (salinizadas), observa-se que a entropia foi menor ao ponto de não provocar grandes distúrbios e eliminar as espécies vegetais. Nesse contexto, não foi detectado, em campo, morte da vegetação provocada pela salinização.

\subsubsection{Parcela de amostragem 3}

Na parcela 3, o solo predominante é o Argissolo Amarelo com características semelhantes ao encontrado na parcela 2. O pH do solo, nessa amostra, foi 6,56 considerado neutro, e o CE $1,88 \mathrm{dSm}^{-1}$ (Tabela 2), que, de acordo com Richards (1954) [26], pode ser considerada uma amostra não salina.

O uso e a cobertura das terras para a parcela 3 (Figura 3C) têm como predomínio a caatinga esparsa com tipologia lenhosa aberta danificada pela criação de animais (caprinos, asininos e ovinos) (Figura 7B). Há, também, pequenas manchas de vegetação herbácea.

A

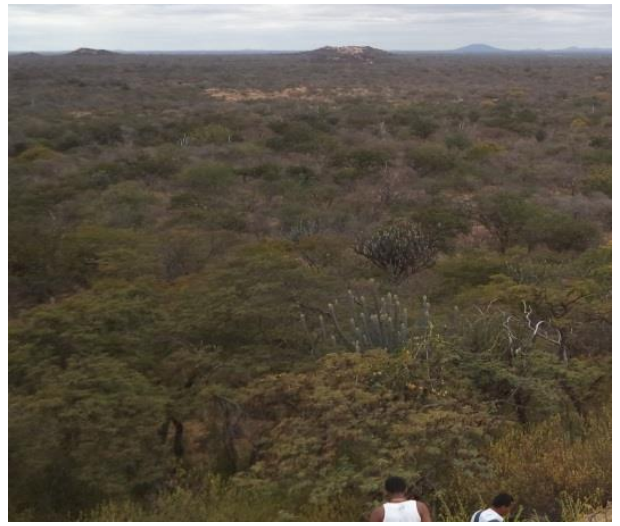

B

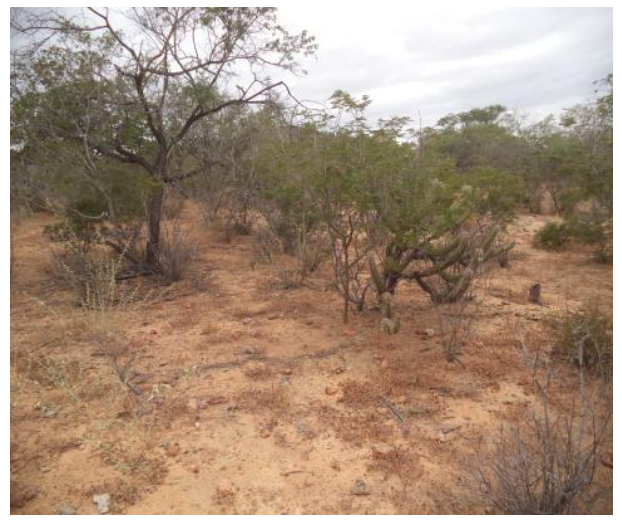

Figura 7: Estrutura da cobertura vegetal na parcela de amostragem 2 e 3: (A) caatinga lenhosa densa na parcela 2 e $(B)$ caatinga esparsa aberta na parcela 3

Em relação à estrutura da vegetação, observa-se a predominância do piso florestal, subdossel e dossel. As espécies vegetais predominantes na estrutura herbácea são o capim, na arbustiva jurema-preta e catingueira (Poincianella pyramidalis). Na estrutura arbórea, predominam o umbuzeiro e o juazeiro, ambos em pequenas quantidades.

Ao se compararem os níveis de salinização do solo com a estrutura da vegetação, observa-se baixa ligação entre ambos, resultados semelhantes aos encontrados na parcela de amostragem 2 . Nesse contexto, ocorreu baixa, ou quase nenhuma, adaptação da vegetação aos graus de salinidade do solo, assim como não houve perdas visíveis de vegetação como ocorreu nas parcelas de amostragens salinizadas ( 1 e 4$)$.

Já nas parcelas 2 e 3, o grau de salinização encontrado após as análises químicas e observacionais em campo indicam que essa área apresenta um grau de colaboração menor ao avanço do processo de desertificação local, em comparação com as parcelas anteriores. Isso porque, nessas áreas foi possível perceber que parte das espécies predominantes, na região, foram encontradas nessas parcelas.

Neste contexto, indica-se que nessas parcelas em que o solo apresentou baixo teor de salinização, o nível de degradação, redução das espécies e baixa biodiversidade das espécies é bem menor em comparação com as parcelas que apresentaram altos valores de salinização. 


\subsection{ALTERNATIVAS PARA CORREÇÃO E APROVEITAMENTO DAS ÁREAS IMPACTADAS PELOS SAIS}

Verificou-se, neste trabalho, que as áreas foram salinizadas por um evento extremo pluviométrico, ou seja, um evento de caráter físico-natural. Nesse sentido, pode-se pensar em alternativas de uso das áreas salinizadas.

Uma das alternativas seria o plantio da erva sal (Atriplex numulária). Essa planta apresenta alta tolerância a ambientes salinos, ou seja, pertence à categoria das halófitas. Santos et al. (2011) [32] destacam que, ao se fixar, no solo, a erva sal, pode extrair os sais, contribuindo no processo de recuperação e/ou reduzir os teores de salinidade dos solos. Esse processo pode ser classificado como fitorremediação.

A erva sal foi introduzida no semiárido brasileiro na primeira metade do século XX. Desse período ao atual, vários estudos foram desenvolvidos para testar e familiarizar essa espécie no território nacional [33]. Testes que vem obtendo excelentes resultados.

Porto et al. (2000) [34] apontam que, nas regiões semiáridas e áridas de várias partes do planeta, a erva sal vem sendo empregada não só para a retirada de sais dos solos, mas também sendo aproveitada para alimentação de animais, com destaque para ovinos e caprinos. $\mathrm{Na}$ área de estudo, o uso da erva sal poderá ajudar na retirada de sais do solo e sua biomassa ser empregada no manejo pecuário, principalmente nos períodos de estiagens.

Outra alternativa seria o uso de corretivos químicos como a aplicação do gesso $\left(\mathrm{CaSO}_{4} \cdot 2 \mathrm{H}_{2} \mathrm{O}\right)$ para substituir o sódio pelo cálcio do complexo dos solos [35]. Este produto químico é de baixo custo e, segundo Tavares et al. (2012) [36] apresenta bons resultados na redução dos níveis de salinização dos solos.

Outros compostos químicos produzem efeitos quase semelhantes ao gesso e podem, também serem utilizados, a exemplo do cloreto de cálcio $\left(\mathrm{CaCl}_{2}\right)$, enxofre $(\mathrm{S})$, carbonato de cálcio $\left(\mathrm{CaCO}_{3}\right)$, óxido de cálcio $(\mathrm{CaO})$, entre outros [6].

Outra opção seria destinar as áreas salinizadas à preservação, visto que todos os cuidados para o desenvolvimento da agricultura nesses locais devem ser tomados, principalmente com o uso da irrigação, o que poderá agravar ainda mais a situação encontrada trazendo sérios prejuízos aos agricultores e expandindo os riscos à desertificação.

\section{CONCLUSÃO}

Percebe-se que a salinização é bastante comum nas regiões áridas e semiáridas do mundo, ou seja, em terras com baixa precipitação pluviométrica. Após a realização desta pesquisa, constatouse que a salinização dos solos, nas parcelas 1 e 4 provocou a redução da vegetação nativa, ocorrendo, assim, a auto-organização do sistema com o surgimento de novas espécies vegetais que não existiam naquela localidade.

Nesse contexto, o recomendado seria a destinação das áreas salinizadas para preservação, visto que qualquer uso poderá acarretar prejuízos para o agricultor. Algumas alternativas foram propostas para o aproveitamento das áreas salinizadas, como a inserção da planta Atriplex, que é uma vegetação capaz de reduzir os sais do solo, além o uso de compostos químicos.

Em relação à desertificação, observa-se que as parcelas com os maiores teores de sais, são aquelas que contribuem para uma maior susceptibilidade à desertificação. Lembrando que, o indicador de salinização por si só não define e não determina se a área está desertificada ou não. $\mathrm{Na}$ verdade, essa classificação é realizada através de um conjunto de indicadores, porém o fato de ter altos teores de sais mexe com a auto-organização do sistema reduzindo o quantitativo de espécies predominantes na área de estudo; alertando para o processo de desertificação do ambiente estudado.

\section{AGRADECIMENTOS}

Ao Ministério do Meio Ambiente (MMA) pela concessão do uso das imagens geradas pelo satélite RapidEye cedida via acordo de cooperação com o primeiro autor. A Coordenação de 
Aperfeiçoamento de Pessoal de Nível Superior (CAPES) pela bolsa de mestrado cedida à terceira autora.

\section{REFERÊNCIAS BIBLIOGRÁFICAS}

1. Wang Y, Yan X. Climate change induced by Southern Hemisphere desertification. Physics and Chemistry of the Earth, Parts A/B/C. 2017 Dec;102:40-47, doi:10.1016/j.pce.2016.03.009.

2. Souza BI, Suertegaray MA, Lima E. R. V. Desertificação e seus efeitos na vegetação e solos do Cariri paraibano. Mercator. 2009;8(16):49-50, doi:10.4215/RM2009.0816.0017.

3. D'odorico P, Bhattachan A, Davis K, Ravi S, Runyan CW. Global desertification: drivers and fee. Advances in water resources. 2012 Jan;51:326-344, doi:10.1016/j.advwatres.2012.01.013.

4. Wijitkosum S. The impact of land use and spatial changes on desertification risk in degraded areas in Thailand. Sustainable Environm Research. 2016 Abr;26:84-92, doi:10.1016/j.serj.2015.11.004.

5. Ribeiro MR. Origem e classificação dos solos afetados por sais. Fortaleza: INCTSal; 2010. Manejo da salinidade na agricultura: estudos básicos e aplicados, p.12-19.

6. Pedrotti A, Chargas RMC, Ramos VC, Prata APN, Lucas AAT, Santos PB. Causas e consequências do processo de salinização dos solos. Rev Eletr Gestão, Educ Tecnol Ambient. 2015 Mai;19(2):13081324, doi:105902/2236117016544.

7. Castro FC, Santos AM. Susceptibilidade ambiental a salinização das terras em municípios da microrregião de Petrolina - Pernambuco - Brasil. Rev Caminhos Geogr, 2015 Dez;16(56):160-172.

8. Brady NC, Weil RR. Acidez, alcalinidade, aridez e salinidade do solo. 3 ed. Rio de Janeiro: Bookman, 2012. A Natureza e propriedades dos solos, p.76-97.

9. Brasileiro RS. Alternativas de desenvolvimento sustentável no semiárido nordestino: da degradação à conservação. Scientia Plena. 2009 Mai;5(5):1-12.

10. Sampaio EVSB, Araújo MSB, Sampaio, YSB. Impactos ambientais da agricultura no processo de desertificação no Nordeste do Brasil. Rev Geogr (Recife). 2005 Jan;22(1):93-113.

11. Dias NS, Blanco FF. Efeitos dos sais no solo das plantas. Fortaleza: INCTSal; 2010. Manejo da Salinidade na Agricultura: Estudos Básicos e Aplicados, p.129-142.

12. Batista MJ, Novaes F, Santos DG. Drenagem como instrumento de dessalinização e prevenção da salinização de solos. 2 ed. Brasília: CODEVASF; 2002. 145p.

13. Bertalanffy LV. Teoria Geral dos Sistemas. Trad. de Francisco M. Guimarães. Petrópolis: Vozes; 1973. $234 \mathrm{p}$.

14. Morin E. O método 1: a natureza da Natureza. 3 ed. Trad. Maria Gabriela de Bragança. Portugal: Publicações Europa-América Ltda.; 1997. 220p.

15. Christofoletti A. Modelagem de sistemas ambientais. 2 ed. São Paulo: Edgar Blücher; 2002. 256p.

16. Amorin RR. Um novo olhar na geografia para os conceitos e aplicações de Geossistemas, sistemas antrópicos e sistemas ambientais. Rev Caminhos Geogr. 2012 Mar;13(41):80-101.

17. Pessoa Junior O. Auto organização e complexidade: uma introdução histórica e crítica. São Paulo: USP; 2003. 198p.

18. Coelho MCN. Impactos ambientais em áreas urbanas: teorias, conceitos e métodos de pesquisa. Rio de Janeiro: Bertrand Brasil; 2001. Impactos ambientais urbanos no Brasil, p.19-45.

19. IBGE. Cidades. Rio de Janeiro: IBGE; 2017. Disponível em: 〈www.ibgecidades.com.br〉. Acesso em: 20 de maio de 2017.

20. Beltrão BA, Mascarenhas JC, Miranda JLF, Souza, LCJ, Galvão MJTG, Pereira, SN. Projeto cadastro de fontes de abastecimento por água subterrânea. Diagnóstico do município de Petrolina, estado de Pernambuco. Recife: CPRM/PRODEEM; 2006. 350p.

21. DINC. Distrito de Irrigação Nilo Coelho. Petrolina: DINC; 2016. Disponível em: <http://www.dinc.org.br/?page_id=98>. Acesso em: 30 de setembro de 2016.

22. Cavalcanti LCS. Cartografia de paisagens. São Paulo: Oficina de Textos; 2014. 96p.

23. Siqueira Filho, JA. Flora das Caatingas do Rio São Francisco: História Natural e Conservação. Rio de Janeiro: Andrea Jakobsson Estúdio Editorial; 2012. p.365.

24. Parplies A, Dubovyk O, Tewes, Mund JP, Schellberg J. Phenomapping of rangelands in South Africa using time series of RapidEye data. Internat J Applied Earth Observ Geoinform. 2016 Dez;53: 90-102, doi:10.1016/j.jag.2016.08.001

25. Cruz ZQ, Ribeiro GP. Ensaios e Segmentação e Classificação Digital de Imagens CBERS Utilizando o Sistema Spring em uma Unidade de Conservação Ambiental Estudo de Caso: Parque Nacional da Serra dos Órgãos (Parnaso). In. Simpósio Brasileiro de Ciências Geodésicas e Tecnologias da Geoinformação; 2008 Out 15-18; Recife: 2008. p.1-9.

26. Richards L. A. Diagnosis and improvement of saline and alkali soils. Washington: Salinity Laboratory; 1954.160p. 
27. EMBRAPA. Centro Nacional de Pesquisa de Solos. Sistema Brasileiro de Classificação de Solos. 2 ed. Brasília: EMBRAPA; 2006. 306p.

28. Al-Soqeer AA, Alsubaie QD, Motawei MI, Mousa HM, Abdel-Salam AM. Isolation and identification of allergens and biogenic amines of Prosopis juliflora genotypes. Electr J Biotechn. 2017 Nov;30(11):24-32, doi.org/10.1016/j.ejbt.2017.08.005.

29. Wakie TT, Laituri M, Evangelista PH. Assessing the distribution and impacts of Prosopis juliflora through participatory approaches. Applied Geography. 2016 Jan;66:132-143, doi:10.1016/j.apgeog.2015.11.017.

30. Wakie TT, Hoag D, Evangelista PH, Luizza M, Laituri M. Is control through utilization a cost effective Prosopis juliflora management strategy? J Environm Manag. 2016 mar;168(1):74-8, doi:10.1016/j.jenvman.2015.11.054.

31. Silva FHBB, Silva AB, Barros AHC. Principais classes de solos do Estado de Pernambuco. Recife: EMBRAPA; 2010. 87p.

32. Santos KCFS, Silva MSL, Silva LE, Miranda MAM, Freire MBGS. Atividade biológica em solo salino sódico saturado por água sob cultivo de Atriplex numularia. Rev Ciência Agron. 2011 Jul;42(3):619627.

33. Porto ER, Dutra MTD, Amorim MCC, Junior LGA. Uso do rejeito da dessalinização de água salobra para irrigação da erva-sal (Atriplex numularia). Rev Bras Eng Agríc Ambient. 2001 Jan;5(1):111-114.

34. Porto ER, Dutra MTD, Amorim MCC, Araújo GGL. Uso de erva sal (Atriplex numularia) como forrageira irrigada com água salina. Petrolina: EMBRAPA, 2000. 67p.

35. Batista MJ, Novaes F, Santos DG, Suguino HH. Drenagem como instrumento de dessalinização e prevenção da salinização de solos. 2 ed. Brasília: CODEVASF; 2002. 124p.

36. Tavares Filho AN, Barros MFC, Rolim MM, Silva EFF. Incorporação de gesso para correção da salinidade e sodicidade de solos salino-sódicos. Rev Bras Eng Agríc Ambient. 2012 Jan;16(3):247-252, doi:10.1590/S1415-43662012000300002. 